Max-Planck-Institut für demografische Forschung

Max Planck Institute for Demographic Research

Konrad-Zuse-Strasse 1 - D-18057 Rostock · GERMANY

Tel +49 (0) 3812081 - 0; Fax +49 (0) 3812081 - 202;

http://www.demogr.mpg.de

MPIDR WORKING PAPER WP 2010-008

FEBRUARY 2010

\title{
Teen Overweight, Weight Stigma, and Intimate Relationship Development from Adolescence to Young Adulthood
}

Yen-hsin Alice Cheng (cheng@demogr.mpg.de)

Nancy S. Landale

This working paper has been approved for release by: Michaela Kreyenfeld (kreyenfeld@demogr.mpg.de), Acting Deputy Head of the Laboratory of Economic and Social Demography.

(C) Copyright is held by the authors.

Working papers of the Max Planck Institute for Demographic Research receive only limited review. Views or opinions expressed in working papers are attributable to the authors and do not necessarily reflect those of the Institute. 
Title:

Teen Overweight, Weight Stigma, and Intimate Relationship Development from Adolescence to Young adulthood*

Authors:

Yen-hsin Alice Cheng

Max Planck Institute for Demographic Research

Nancy S. Landale

Pennsylvania State University

* Direct correspondence to: Yen-hsin Alice Cheng, Max Planck Institute for Demographic Research, Konrad-Zuse-Str. 1, 18057 Rostock, Germany. Tel: 49-381-2081245. Fax: 49-3812081545. Email: cheng@demogr.mpg.de

Support for this research was provided by a grant from the NICHD, R01-HD045309. Support services were provided by the Population Research Institute, Pennsylvania State University, which has core support from the NICHD (R24-HD41025). This research uses data from Add Health, a program project designed by J. Richard Udry, Peter S. Bearman, and Kathleen Mullan Harris, and funded by a grant P01-HD31921 from the Eunice Kennedy Shriver National Institute of Child Health and Human Development, with cooperative funding from 17 other agencies. Special acknowledgment is due Ronald R. Rindfuss and Barbara Entwisle for assistance in the original design. Persons interested in obtaining data files from Add Health should contact Add Health, Carolina Population Center, 123 W. Franklin Street, Chapel Hill, NC 27516-2524 (addhealth@unc.edu). No direct support was received from grant P01-HD31921 for this analysis. 


\title{
Teen Overweight, Weight Stigma, and Intimate Relationship Development from Adolescence to Young adulthood
}

\begin{abstract}
With an emphasis on how weight stigma is manifested in social relationship context, this study explores two under-studied consequences of adolescent overweight, timing of first sex and subsequent intimate relationship development. The data employed come from Waves I to III of the National Longitudinal Study of Adolescent Health. The results indicate that overweight adolescents have significantly later onset of first sex and are more likely to enter early adulthood without any intimate relationship experience when compared to normal-weight youth.

Overweight adolescents are vulnerable to discriminatory treatments such as being rejected by or having less close relationships with peers and are thus less likely to have any intimate relationship. The study contributes to the existing literature on overweight youth by revealing the critical role of prejudiced social encounters in peer relationships as the key context that hinders the development of intimate relationships from adolescence to early adulthood. Future studies should seek to understand the broader implications of poor social adjustments during adolescence for later development.
\end{abstract}

Key words: adolescent overweight, weight stigma, sex debut, intimate relationship, sexual development, social relationships 
Obesity has become an increasingly prevalent health problem during the past few decades in the United States. Between the 1960s and 2002, the prevalence of overweight among 12- through 19-year-olds more than tripled--from 5\% to 17\% (NCHS 2005). Weight-based stigmatization toward overweight children has been documented over the past few decades (Puhl and Latner 2007). A stigmatized child often encounters social exclusion, derogatory comments, and physical bullying, etc. With the increase in overweight prevalence, weight stigma toward children did not improve but worsened than four decades ago (Latner and Stunkard 2003). The majority of studies that have investigated the impact of weight bias toward overweight adolescents focus on a variety of outcomes such as psychosocial adjustment, academic and SES consequences, and physical health (Puhl and Latner 2007). Amidst all the existing studies, a relatively underexplored issue is how weight stigma shapes romantic relationship and sexual experiences of overweight adolescents.

The development of intimate relationships, here defined as romantic relationships that involve sexual behaviors, is an indicator of youths' physiosocial well-being. On the physiological side of health, a potential "paradox" exists in the research on teen overweight and intimate relationship development. The fact that overweight teens are less likely to date (Halpern, King, Oslak, and Udry 2005) indicates that they have a relatively low risk of initiating sex, since first sexual intercourse generally occurs in a steady relationship (Ryan, Manlove, and Franzetta 2003). Early sex debut is considered risky in the adolescent development literature (Hofferth 1987). Thus, although being overweight is associated with negative health and social outcomes, overweight teens are somewhat "protected" from experiencing this negative event. Although overweight could be a factor that contributes to risky sexual development. Evidence from a number of clinical cases suggests that some obese adults become sexually promiscuous as a way 
of seeking approval from the opposite sex or releasing grievances that result from weight discrimination (McDanal Jr 1993). Although a similar problem has not been documented in the adolescent literature, sexual promiscuity in adulthood could potentially have roots in adolescence. Even if overweight adolescents are not engaging in risky sexual acts, they may still be more likely to give in to romantic partners' sexual advances because of a fear that their refusal may jeopardize the relationship. Therefore, the influence of overweight on adolescents' physio-sexual development may be complex. It is imperative for researchers to understand more about how body weight shapes this process during adolescence and early adulthood. The existing sparse research on this issue has not investigated it from a developmental perspective.

On the social side of health, prior research has shown that adolescent sexual behaviors occur mostly in steady, romantic relationships (Downey, Bonica, and Rincon 1999; Ryan, Manlove, and Franzetta 2003). In turn, studying intimate relationships in adolescence is not only about the emergence of sex, but also about how close interpersonal relationships shift from same-sex crowds to the opposite-sex. As noted, overweight youth tend to have more problems developing romantic relationships (Halpern, King, Oslak, and Udry 2005; Halpern, Udry, Campbell, and Suchindran 1999). This could potentially be attributed to the fact that adolescent overweight increases the likelihood of being marginalized by peers (Pearce, Boergers, and Prinstein 2002; Strauss and Pollack 2003), which then reduces the chances of dating. Connolly and colleagues (2000) found that adolescents with more other-sex friends or friends from other schools in their social networks are more likely to have romantic relationships. They pointed out that while other-sex friendship networks have a direct effect on romantic relationships, same-sex networks have an indirect effect (Connolly, Furman, and Konarski 2000). The formation of intimate relationships is an important part of human development during adolescence. If overweight 
youths have limited opportunities to experience or to explore intimate relationships, chances are they may continue to have trouble forming stable and healthy dyadic relationships as adults. This can potentially be a crucial reason why the likelihood of marriage is relatively lower for overweight individuals (Gortmaker, Must, Perrin, Sobol, and Dietz 1993).

A good starting point to unravel the process of intimate relationship development is examination of how adolescent weight status affects the emergence of first sex, as it is an important developmental marker. Research has shown that overweight is associated with lower likelihood of having sex, yet little is known about whether being overweight is linked to significantly later timing of first sex at the population level. Furthermore, little is known about why overweight is associated with delayed initiation of first coitus. Researchers studying the consequences of adolescent overweight know equally little about the development of intimate sexual relationships from adolescence to young adulthood. As adolescents make the transition to first sex, how does their developmental trajectory of intimate relationships evolve? Who are the adolescents who remain sexually inexperienced throughout their adolescence? Is the trajectory followed affected by weight status? The best way to study the developmental trajectories of adolescents is to track relationship experiences over several years, so that a more complete picture can be seen.

This study seeks to contribute to the paucity of related research by addressing three major questions: (1) What is the association between weight status and the timing of first sex in adolescence? (2) How does intimate relationship develop across the entire span of adolescence and early adulthood for adolescents of different weight statuses? (3) How does weight stigma shape the mechanisms that explain these processes? The current study utilizes a nationally representative sample from three waves of the National Longitudinal Study of Adolescent Health 
(Add Health) to examine how weight status affects adolescents' sexual development.

\section{Conceptual Framework}

\section{Weight Stigma in Social Relationships}

Weight stigma refers to biased attitudes toward individuals with excessive weight that are often expressed in prejudice and rejection. A stigmatized individual often encounters overt and covert victimization such as teasing, bullying, or social exclusion or avoidance. Empirical research on weight stigma and the negative adjustments of overweight youth suggests that weight-based teasing and victimization, instead of body weight per se, are the crucial factors leading to unfavorable outcomes. Similar processes have been found in studies about psychological adjustment, dating opportunities, socioeconomic outcomes, and physical health consequences (Puhl and Latner 2007). Existing research has not explored the role of social relationships in mediating the effect of body weight on sex debut and subsequent intimate relationship

development. Researchers know that overweight is associated with lower likelihood of initiating an intimate relationship (Halpern et al. 1999; Halpern et al. 2005), yet little is known about whether being overweight is linked to significantly later sex debut at the population level and the underlying processes that cause it.

Cawley and colleagues (2006), who used the National Longitudinal Study of Youth 1997 (NLSY 97) and the Add Health data to examine how height, weight, and BMI relate to dating and sexual activities in adolescence. They reported that overweight adolescents are less likely to have first sex in the Add Health data, but not in the NLSY 97 (Cawley et al. 2006). There are two major limitations to their study. First, they used adult BMI cutoff standards (i.e., BMI $<18.5$, 18.5-25, 25-30, >30) to categorize adolescent BMI values into underweight, normal weight, overweight, and obese. Given the wide age range (ages 12 to 20 in Wave 1) of the sample in the 
Add Health study and the different developmental pace of boys and girls, using adult standards can misclassify younger overweight adolescents as having normal weight. For example, a BMI of 24 is over the 85 percentile for a 14-year-old, but it is considered normal weight in the adult population. Thus, the 2000 CDC growth charts are more ideal for making age- and sex-sensitive cutpoints for studying overweight in adolescence (Ogden, Kuczmarski, Flegal, Mei, Guo, Wei, Grummer-Strawn, Curtin, Roche, and Johnson 2002). Second, Cawley and colleagues did not seek to study the mechanisms underlying the association between weight and timing of sex debut. As suggested by earlier research, romantic relationships provide the context for sexual activities (Halpern, Udry, Campbell, and Suchindran 1999), especially first sexual intercourse (about 85\%) in adolescence (Ryan, Manlove, and Franzetta 2003). Since adolescent romantic relationships often evolve from social interactions with the opposite sex in mixed-gender peer groups (Connolly, Craig, Goldberg, and Pepler 2004), interpersonal relationships in adolescence become a key context to examine if researchers want to gain further insight into how body weight affects intimate relationship development.

Social relationships occupy a central position in adolescence, and the peer context is an incubator for the emergence of romantic relationships (Brown 1999; Cavanagh 2007). Both same-sex and other-sex friendships affect the formation of romantic relationships in adolescence (Connolly, Furman, and Konarski 2000). A study by Cavanagh (2007) also showed that youth who are closer with their female friends are more likely to initiate a romantic relationship, whether it is sexual or not. This is partly because girls integrate their friendship network faster than boys (Feiring 1999). Furthermore, deeper involvement in peer groups (especially with opposite-sex friends) increases the odds of first sex within dating relationships (Sieving, Eisenberg, Pettingell, and Skay 2006). Closer relationships with both male and female friends 
among White youth are also related to more sexualized conceptions of romantic relationships (Cavanagh, 2007).

Adolescent overweight influences social relationships by increasing the likelihood of discriminatory treatment by peers (Pearce, Boergers, and Prinstein 2002; Strauss and Pollack 2003), which then reduces the chances of dating. A few studies have reported that overweight adolescents are more likely to be bullied and to be isolated from peer networks than their normal weight peers (Pearce, Boergers, and Prinstein 2002; Strauss and Pollack 2003). In Strauss and Pollack’s (2003) study, overweight adolescents received significantly fewer friendship nominations from others when compared to normal weight adolescents. Overweight teens were much more likely to receive no friendship nominations and when they did receive any, most of them were from less popular youth. It was also found that increased participation in sports was associated with significantly more friendship nominations (Strauss and Pollack 2003). It follows that if overweight adolescents have greater difficulties developing friendships with peers, they will have fewer opportunities to experience a romantic relationship. Without the experience of a romantic relationship, the chances of sexual initiation are even lower for overweight teens. As pointed out by Thornton (1990), the probability that an adolescent reports having sexual intercourse is related to the age at which first dating took place, and there is a significant increase in the proportion who have experienced sexual intercourse about one year after the first steady dating relationship starts.

If overweight adolescents are likely to be nominated by less popular teens as friends or to be friends with other teens who are more peripheral to the peer networks, the likelihood that they will develop a romantic relationship or engage in sexual activity becomes equally low. Thus, it is hypothesized that overweight is associated with later onset of first coitus (H1) and that social 
relationships mediate the influence of body weight on sex debut in adolescence (H2).

\section{Research Related to the Developmental Trajectory of Intimate Relationships}

The trajectory of intimate relationships is one aspect of human development that has yet to be analyzed in relation to body weight. It has been documented that some very overweight individuals seem to engage in risky sexual activities with multiple partners (Kiess and Boettner 2002; McDanal Jr 1993), yet the empirical literature has not assessed whether overweight elevates such risk at the population level or among adolescents. While overweight can create problem behaviors, it is reasonable to believe that many overweight adolescents do not experience problems with respect to their sexual development. In fact, based on the review in earlier sections, if overweight youth were to experience any adjustment issues, the problems are more likely to stem from delayed or limited intimate relationship development, rather than from having too many such experiences.

Empirical studies on the developmental trajectories of intimate relationships among youth are almost nonexistent. One reason for this dearth of knowledge is limited data on relationship experience. Surveys rarely collect complete histories of respondents’ past intimate relationships. Given that adolescence is a transitional phase from childhood to adulthood, in which a great amount of physical change and identity exploration take place, sexual activities can vary over time. When information regarding the start and end dates of each intimate relationship is not known, it is difficult for researchers to know how active individuals are sexually at each age over a period of time.

Based on the limited current knowledge about developmental trajectories of intimate relationships, we know that teens who start dating at a younger age have more sexual partners by age 18 (Thornton 1990). Early onset of first sexual intercourse is associated with more life-time 
sexual partners or having multiple sexual partners at one time (Santelli, Brener, Lowry, Bhatt, and Zabin 1998; Thornton 1990). Given the association between early first sex and subsequent sexual risk behaviors, one would think that the factors leading to early sex debut also predict later intimate relationship development.

Indeed, individuals who report more sexual partners are found to be less conventional. They are less religious, more prone to risk-taking behaviors, and more likely to use drugs or alcohol than those with fewer partners (Santelli et al. 1998). Individuals with higher GPAs have fewer sexual partners (Luster and Small 1994). Another study showed that intelligent adolescents (measured by Peabody Picture Vocabulary Test scores) are less likely to engage in early sex, which protects them from later unfavorable consequences (Halpern, Joyner, Udry, and Suchindran 2000). In addition, stronger parental monitoring and supervision are associated with decreased sexual risk behaviors (Jemmott and Jemmott 1992). Thus, it is hypothesized that risk factors associated with early first sex will likely predict membership in riskier intimate relationship trajectories (H3).

\section{Research Design}

\section{Data}

The data used for the current study come from the National Longitudinal Study of Adolescent Health (Add Health). Add Health was designed to study health behaviors of a cohort of adolescents who were in grades 7-12 during the 1994-1995 academic year. Students were selected from a representative sample of U.S. high schools with a known probability sampling method. Minority groups, including Asians, Puerto Ricans, and African Americans from welleducated families, were oversampled (Harris, Florey, Tabor, Bearman, Jones, and Udry 2003).

The data were collected mainly through adolescent in-home interviews that gather 
information about daily activities, risky behaviors, intimate relationships, and other developmental and health indicators. The first wave of Add Health was collected between September 1994 and December 1995. A follow-up Wave 2 interview was done between April 1996 and August 1996. Finally, the Wave 3 interview was conducted with respondents in young adulthood between 2001 and 2002.

This study also utilizes the network data that were constructed from adolescents' friendship nominations at Wave 1 . The network data link friendship nominations sent and received by each individual respondent in the in-school questionnaire. This special data file provides important information regarding structural properties of friendship networks among adolescent peer groups. One key feature to be noted is that this network file only makes use of reports from respondents who attended schools that have response rates of 50 percent or higher. It is generally more difficult to offer reasonable estimates of the network structure if a school has a response rate lower than 50 percent (Moody 2005).

\section{Study Sample}

The adolescents being studied are those who participated in all three waves of Add Health and have valid longitudinal sample weights. There are a total of 11,621 respondents who were interviewed in all three waves. Of these adolescents, 793 did not have a valid longitudinal sampling weight and were excluded from this study. Adolescents who had sex before the Wave 2

interview ( $\mathrm{n}=3,923$, about $34 \%$ ) were left-censored from the study. ${ }^{1}$ We examine the transition to first sex and sexual trajectories from Wave 2 forward because objective height and weight were not available in Wave 1. Although a prior study has shown that self-reported height and weight, which were reported in Wave 1, are reliable for 96\% of the adolescents in Add Health (Goodman, Hinden, and Khandelwal 2000), a closer look at the Body Mass Index (BMI) ${ }^{2}$ data showed 
inaccurate reports among overweight and underweight individuals (i.e., reported BMI values lower than measured BMI values among the overweight and higher among the underweight). Hence, measured BMI in Wave 2 is used instead of Wave 1 subjective reports. ${ }^{3}$ Given that the key predictor, weight status, is taken from Wave 2, it was not possible to include adolescents who had made the transition to first sex prior to Wave 2. The final sample is 6,905 adolescents between the ages of 12 and 21 in the academic year 1994-1995.

\section{Variables and Measures}

\section{Outcome Variable}

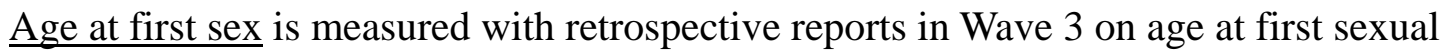
intercourse. Inconsistent reports of age at sex debut and relevant coping strategies for researchers have been discussed in a study by Upchurch and colleagues (Upchurch, Lillard, Aneshensel, and Fang Li 2002). ${ }^{4}$ Thus, in addition to Wave 3 reports, Wave 2 reports on age at sex debut were used to check data consistency. Several strategies were adopted to deal with a small number of inconsistent reports. If an adolescent reported different ages at first sex in Waves 2 and 3, the average of the 2 reports is used. If an adolescent reported age at first sex in Wave 2 but indicated he or she never had sex in Wave 3, the Wave 2 report is used. The final data show that 1,161 adolescents had never had sex by the Wave 3 interview. Age at first sex is used to measure whether or not each adolescent had experienced sexual intercourse by a given age. Intimate relationship trajectories: The construction of the intimate relationship trajectories involved two steps: creating age-specific counts of intimate relationships in a given year and extracting trajectories from the age-specific reports using a mixture modeling technique. In Wave 3 of Add Health, adolescents were asked to report any romantic relationship they were involved in since the Wave 2 interview. In addition to the start and end dates of each relationship, 
the date of the first sexual intercourse within a relationship was recorded. Given that $90 \%$ of all relationships reported in Wave 3 are sexual in nature, tracking all of these sexual relationships reported by each respondent offers a near complete picture of his/her intimate relationship development trajectory. The start and end dates of each relationship in the respondent's history were coded in century-month format. After matching these relationship dates to the beginning and end century months of each year of age of a respondent, an age-specific count of the number of intimate relationships was constructed for each respondent. After these age-specific observations were created for each respondent, a group-based mixture modeling technique (Nagin 2005) was utilized to extract several distinct trajectories embedded in these data.

\section{Predictors and Control Variables}

Weight status is constructed using BMI values calculated from measured height and weight in Wave 2. Weight statuses are constructed by categorizing BMI values into underweight, normal weight, at risk of overweight, and overweight, based on the age- and sex-adjusted standards published in the Centers for Disease Control growth chart. Adolescent underweight is defined as BMI values that fall at or below the $5^{\text {th }}$ percentile of the age- and sex- specific BMI distribution. BMI values that fall between the $5^{\text {th }}$ and $85^{\text {th }}$ percentiles are defined as normal weight. At risk of overweight is defined as a BMI value that is between the $85^{\text {th }}$ and $95^{\text {th }}$ percentiles. Finally, BMI value above the $95^{\text {th }}$ percentile are categorized as overweight.

Sociodemographic characteristics: Sociodemographic variables were constructed from the Wave 1 in-home questionnaire. These include age at Wave 1 , gender, race, maternal education, family structure, and family income. Race is a four-category variable that consists of White, Black, Hispanic, and other races. Maternal education is a four-category variable that is coded as less than high school, high school graduate, some college and college or beyond. Family structure is 
also a categorical variable that shows four types of families: two-biological-parent families, stepfamilies, single-parent families and other families. Research has shown that adolescents who have better-educated mothers are more likely to delay first sexual intercourse (Manlove, Ryan, and Franzetta 2007). Living with two biological parents protects adolescents from experiencing early first intercourse (Crockett, Raymond Bingham, Chopak, and Vicary 1996). Finally, family income is measured in thousands and is reported by parents in the Wave 1 parental questionnaire. Factors related to first sex: Based on prior research on adolescent sexual behaviors, Wave 1 characteristics that are closely associated with initiation of first sex are also controlled in the models. These include mother-child closeness, positive family climate, self-reported grades, school adjustment, self-esteem, religiosity, respondent's attractiveness, motivation to have sex, and perceived social consequences of sex. Studies have looked at various factors that lead to early sexual initiation in adolescence. As for family influences, a close mother-child relationship (Sieving, McNeely, and Blum 2000) or positive family climate (Bingham and Crockett 1996) predict later onset of first sex. Adolescents who perceive strong maternal disapproval of sex also are more likely to delay first sex (Dittus and Jaccard 2000).

Adolescent characteristics are also associated with early sex debut. Teens who started dating at younger ages are more at risk of early first sex (Thornton 1990). Furthermore, adolescents who have more permissive attitudes toward sexual behavior are more inclined than others to have sex at a young age (Buhi and Goodson 2007). Conventional values and behaviors such as greater educational investment (e.g., better grades, stronger academic aspirations, etc.) (Costa, Jessor, Donovan, and Fortenberry 1995) and stronger religiosity delay the onset of first sex (Crockett, Raymond Bingham, Chopak, and Vicary 1996). Using the problem behavior theory, Costa and colleagues (1995) found that psychosocial unconventionality (i.e., tolerance of 
deviance, greater influence from friends than from parents, having friends with problem behaviors, low school achievement, etc.) are linked to early first sex (Costa, Jessor, Donovan, and Fortenberry 1995).

The relationship between self-esteem and onset of first sex is complex and related to adolescents' values (Whitbeck, Yoder, Hoyt, and Conger 1999). While some studies show a link between self-esteem and early intercourse (Crockett, Raymond Bingham, Chopak, and Vicary 1996), others have indicated that the relationship varies by an adolescent's belief about early sex (Miller, Christensen, and Olson 1987). Self-esteem is only positively related to early sex for those who think early first sex is acceptable.

Mother-child closeness is a scale that sums up four items: (1) Most of the time, your mother is warm and loving toward you; (2) When you do something wrong that is important, your mother talks about it; (3) You are satisfied with the way your mother and you communicate with each other; and (4) Overall, you are satisfied with your relationship with your mother. Cronbach's alpha for this scale is 0.84 . Positive family climate is measured by adding three items: How much do you feel that (1) people in your family understand you? (2) you and your family have fun together? (3) your family pays attention to you? Cronbach's alpha for this scale is 0.79 . Selfreported grades is a composite measure of the average grade in four subject areas: English, math, history, and science. Grades reported for each subject are summed and divided by four to construct a single measure for academic performance. School adjustment is measured by six items: (1) You feel close to people at your school; (2) You feel like you are part of your school; (3) Students at your school are prejudiced; (4) You are happy to be at your school; (5) The teachers at your school treat students fairly; and (6) You feel safe in your school. After item (3) was reverse coded, these six items are added together to construct a single measure of school 
adjustment. The Cronbach's alpha for this scale is 0.72 . Self esteem is a scale made by adding seven items together. These items are: (1) You have a lot of good qualities; (2) You are physically fit; (3) You have a lot to be proud of; (4) You like yourself just the way you are; (5) You feel like you are doing everything just about right; (6) You feel socially accepted; (7) You feel loved and wanted. The Cronbach's alpha for this scale is 0.85 . Religiosity measures how often respondents pray or attend religious activities. It is constructed by three items: How often do you (1) attend religious services? (2) pray? (3) attend youth religious activities? The Cronbach's Alpha for this scale is 0.63 . Motivation to have sex and perceived social consequences of sex are two composite variables. "Motivation to have sex" contains items like: If you had sexual intercourse, (1) your friends would respect you more; (2) it would give you a great deal of physical pleasure; (3) it would relax you; (4) it would make you more attractive to women; (5) you would feel less lonely. The Cronbach’s Alpha for this scale is 0.77 . "Perceived social consequences of sex" consists of three variables: If you had sexual intercourse, (1) your partner would lose respect for you; (2) you would feel guilty afterward; (3) it would upset your mother. The Cronbach's Alpha for this scale is 0.67. Finally, attractiveness of the respondent is measured using the interviewer's response to the question: How physically attractive is the respondent? Respondents were rated using a 5-point Likert scale ranging from "very unattractive” to "very attractive.” Weight-based social relationship characteristics: Respondents' social relationships are measured using six variables/scales reported in the Wave1 and Wave 2 interviews. These measures tap into different aspects of an adolescent's connections with people around him/her. Only the dichotomous measure of ever had a romantic relationship is measured at Wave 2; all other variables are reports at Wave 1. Ever had a romantic relationship is measured using the question: Have you ever had a romantic relationship? Feeling of social marginalization is a scale that sums 
up three items: (1) You feel lonely; (2) You feel people are unfriendly to you; (3) You feel disliked by people. The Cronbach’s Alpha for this scale is .64. The next three variables measure adolescents' friendships and involvement with peers. The network file at Wave 1 is utilized to get the total number of friendship nominations received by each respondent. ${ }^{5}$ This variable is used as a proxy for popularity. Closeness with same-sex friends and closeness with opposite-sex friends are also constructed from the data in the network file. Adolescents were asked to nominate up to five male and five female friends in the network file and to report their activities with these friends during the past week. A series of questions were asked of each respondent to measure his/her closeness with the nominated friends. These items are: In the past seven days, did you (1) go to friend's house? (2) meet friend after school to hang out or go somewhere? (3) spend time with friend? (4) talk to friend about a problem? (5) talk to friend on the telephone? Responses to these questions were added across friends of the same gender to construct "activities with male friends" and "activities with female friends". Then, the respondent’s gender is matched with "activities with male/female friends" to construct scales measuring "closeness with same-sex friends" and "closeness with opposite-sex friends." The Cronbach's alpha for the closeness measure is 0.70 . Participation in a team sport during the past week is measured by the question: "During the past week, how many times did you play an active sport, such as baseball, softball, basketball, soccer, swimming, or football?” The range of response values is from 0 to 3 .

\section{Missing Values and Complex Survey Design}

Missing data are handled using the multiple imputation procedure (Proc MI) in SAS. Five imputed datasets were generated using the Proc MI procedure in SAS. Multiple imputation (Rubin 2004) is a procedure that utilizes a Monte Carlo technique to replace missing values with several simulated versions. In Rubin's method for repeated imputation inference, each of the 
simulated complete datasets is analyzed by standard methods, and the results are combined to produce estimates and confidence intervals that incorporate missing-data uncertainty (http://www.stat.psu.edu/\%7Ejls/mifaq.html - ref). In the analyses that follow, both descriptive statistics and the output for regression models are based on the combined outputs from five imputed datasets using Rubin's rule. The complex survey design of the Add Health data is taken into account using the SAS-callable SUDAAN program. Appropriate longitudinal sampling weights are applied to the statistical models. In addition, clustering and stratifying variables are both taken into account to adjust the standard errors.

\section{Statistical Analyses}

Descriptive statistics are presented to offer an overview of the study sample. Discrete-time event history models are used to examine the effects of weight status and social relationship variables on the timing of the transition to first sex. A person-year file was created for each year of observation between the age at Wave 2 and the age when the first sexual intercourse occurred. If a respondent never experienced first sex, the last observation is the age at which the Wave 3 interview was conducted. A dichotomous outcome variable indicating whether or not a respondent experienced first sex at a given age was created to mark the transition. This variable is coded ' 0 ' until the age at which first sex occurred, when it is coded ' 1 .' A series of nested discrete-time event history models were fit. To investigate the different developmental meanings of weight status and first sex in two stages of adolescence, the person-year file was further separated into one file that contains exposure ages younger than 18 and another file with exposure ages at and above 18. These two datasets were used for separate event history models that include the same predictors shown in the models using the pooled sample.

For the analyses of intimate relationship trajectories, a group-based modeling technique was 
used to extract developmental trajectories of intimate relationships from adolescence to young adulthood. The method is a form of finite mixture modeling that identifies distinctive groups of developmental trajectories within a population based on a repeatedly measured outcome variable. This modeling approach estimates a set of parameters that define the shapes of several different trajectories and calculates the probability of trajectory group memberships for each respondent.

Nagin and colleagues developed a SAS procedure called PROC TRAJ to fit this type of model for longitudinal data. This procedure performs data sequence grouping and estimates different parameter values for the data distribution of each trajectory. Age-specific observations of the number of sexual relationships between Waves 2 and 3 (about 6 years) were constructed using the procedures discussed earlier to model the longitudinal development of sexuality. After the various trajectories were identified, a 4-group categorical outcome variable was created. Weight status and the entire array of variables used in the models of transition to first sex were entered into a multinomial logistic regression to see how they predict membership in the sexual trajectories.

\section{Results}

\section{Descriptive Analysis}

Table 1 shows weighted summary statistics for the variables characterizing the study sample. Ttests are performed within each variable across weight statuses, using the normal-weight category as the reference group. Overweight adolescents are significantly less likely to make the transition to first sex between Wave 2 and Wave 3. About 85\% of normal weight adolescents had first sex by Wave 3, compared to $79 \%$ of overweight teens.

-- Table 1 about here --

The next panel presents basic sociodemographic characteristics of the study sample. 
Overweight teens are more likely to be male and Black than normal-weight teens. A significantly higher percentage of overweight teens compared to normal-weight teens come from a singleparent family. When compared to normal-weight adolescents, overweight youth are significantly more likely to have a mother who completed high school or some college education, but less likely to have a mother with less than high school or a college degree. The overweight youth also tend to live in families with significantly lower family income than the normal-weight youth. For factors related to sex debut, overweight adolescents report lower grades, lower school adjustment, and lower self-esteem. They are rated lower on physical attractiveness as well. With regard to social relationships, overweight teens report much higher scores on feeling socially marginalized than normal-weight teens. They receive fewer friendship nominations, report lower closeness with same-sex and opposite-sex friends, are less likely to participate in a team sport in the past week or to have had a romantic relationship, relative to normal-weight adolescents. The profile of at risk of overweight youth is quite similar to that of overweight youth.

\section{Transition to First Sex}

Table 2 shows a series of nested event history models that examine the effect of weight status on the hazard of first sex. In the baseline Model 1, there is a negative relationship between being overweight $(\mathrm{OR}=0.82, \mathrm{p}<.01)$ and the timing of first sex. Overweight adolescents are significantly less likely to make the transition to first coitus, when compared to their normalweight peers. The lower likelihood of initiating first sex for overweight adolescents persists until Model 4. In Model 4, after the introduction of the social relationship variables, the odds ratio for overweight is only marginally significant $(\mathrm{OR}=0.89, \mathrm{p}<.10)$.

-- Table 2 about here --

The results in Models 3 and 4 show that the association between weight status and the odds 
of first intercourse is largely mediated by social relationship factors. Adolescents who feel socially marginalized by peers have a much lower likelihood of initiating first sex ( $\mathrm{OR}=0.95$, $\mathrm{p}<.01)$. On the other hand, receiving more friendship nominations ( $\mathrm{OR}=1.03, \mathrm{p}<.001)$, closeness with same-sex friends ( $\mathrm{OR}=1.02, \mathrm{p}<.001)$, having participated in a team sport during the past week (OR=1.07, $\mathrm{p}<.01)$, and having had a romantic relationship prior to Wave $2(\mathrm{OR}=1.72$, $\mathrm{p}<.001$ ) increase the odds of sex debut between Wave 2 and Wave 3. Additional analyses (results not shown) indicate that the attenuation of the odds ratios for being overweight is not mainly due to the experience of having a romantic relationship by Wave 2, but by all six social relationship variables added in Model 4.

\section{Subanalyses by Exposure Age}

Sexual experiences during early or mid-adolescence have different developmental meaning than those during late adolescence and early adulthood. Sexual activity becomes more normative in late adolescence than it is in early to mid-adolescence. In Table 3, Model 1 indicates that during early and mid-adolescence, overweight youth have a lower likelihood of initiating first sex $(\mathrm{OR}=0.84, \mathrm{p}<.05)$. The odds ratio for overweight status is reduced to nonsignificance in Model 4 after the addition of the social relationship variables. Younger adolescents who feel socially marginalized are less likely to make the transition to first sex. Receiving more friendship nominations, higher closeness with opposite-sex friends, and having had a romantic relationship all expedite the onset of first intercourse.

-- Table 3 about here --

In contrast, the models for the older ages in Table 3 show that the negative association between overweight and sex debut $(\mathrm{OR}=0.79, \mathrm{p}<.01)$ is quite robust in Models 1 to 4 . The inclusion of the social relationship variables does not explain the association (OR=0.85, $\mathrm{p}<.05)$ 
in Model 4. The effects of various factors that increase the odds of sex debut are in the expected directions. Finally, more received friendship nominations, closer relationships with same-sex friends, having played a team sport in the past week, and having had a romantic relationship in adolescence all raise the likelihood of first coitus during late adolescence and early adulthood.

\section{Extracting Developmental Trajectories of Intimate Relationships}

The results of group-based modeling indicate four distinct trajectories/groups based on intimate relationship histories (see Figure 1). ${ }^{6}$ The four trajectories are very different in terms of their developmental meaning. The X-axis in Figure 1 represents the six observed years of age in the data. Each point has adolescents at various ages, depending on their age at Wave 2. For a 14year-old adolescent at Wave 2, Age1 to Age6 on the X-axis correspond to ages 14 to 19, while for a 16-year-old adolescent the corresponding ages are 16 to 21.

-- Figure 1 about here --

The first line from the top is a trajectory for adolescents with a high-risk sexual history involving multiple partners. Only about 3\% of the study sample belongs to this group. The next line is a trajectory depicting adolescents who almost always have one sexual partner throughout the six observation points. It should be noted that some of the respondents in this trajectory have two partners or even no partner in a given year. For example, the six data points for them may look like $(1,1,1,1,2,1),(1,1,0,2,1,1)$ or $(1,1,1,2,2,1)$. But, since they have one partner most of the time, these respondents are grouped into this trajectory. The third line shows the trajectory that is usually considered “developmentally sound.” That is, adolescents transition from having no sexual relationship to having the first relationship as they enter late adolescence or early adulthood. Finally, the line in the bottom of the graph describes those who never had any sexual relationship throughout the six observed ages, and thus shows a flat trajectory. 


\section{Predicting Trajectory Memberships}

After extracting the four trajectories from the observed annual sexual relationship data, the groupings are used as the outcome variable for a series of nested multinomial logistic regression models. The reference category is the never-had-sex trajectory (Trajectory 4). Table 4 presents models predicting the various trajectories. Overweight adolescents are less likely to be in the high-risk trajectory $(\mathrm{OR}=0.50, \mathrm{p}<.05)$, constant-one-partner $(\mathrm{OR}=0.61, \mathrm{p}<.001)$, and progression-to-one $(\mathrm{OR}=0.75, \mathrm{p}<.05)$ trajectories than to be in the never-had-sex trajectory, when compared to normal-weight adolescents. Overweight teens' lower likelihood of being in these trajectories is attenuated but still significant in Model 2 after sociodemographic characteristics are considered. In Model 3, which adds additional Wave 1 variables related to first sex in prior studies, overweight adolescents' lower odds of being in the high-risk (OR=0.50, $\mathrm{p}<.10)$ and progression-to-one-partner $(\mathrm{OR}=0.77, \mathrm{p}<.10)$ trajectories are only marginally significant. The odds of consistently having one partner remain significantly lower for overweight adolescents compared to normal-weight adolescents $(\mathrm{OR}=0.60, \mathrm{p}<.01)$. Finally, the weight status differences are essentially eliminated in Model 4, which adds the social relationship variables. A marginally significant difference between overweight and normal-weight adolescents remains $(\mathrm{OR}=0.75, \mathrm{p}<10)$ for membership in the constant-one-partner trajectory.

-- Table 4 about here --

Overall, adolescents' social relationships appear to play an important role in the relationship between body weight and intimate relationship trajectories. Popularity in peer groups (as indicated by more received friendship nominations) and having had romantic relationship experience in adolescence are both associated with higher odds of being in all three sexual trajectories other than the reference group (the never-had-sex trajectory). The impact of romantic 
relationship experience is especially strong for the high-risk trajectory $(\mathrm{OR}=8.91, \mathrm{p}<.001)$, but still important for the constant-one-partner trajectory $(\mathrm{OR}=3.84, \mathrm{p}<.001)$ and the progression-toone-partner trajectory $(\mathrm{OR}=1.98, \mathrm{p}<.001)$. Closer ties with friends and participating in group activities with peers increase the odds of having one partner consistently or progressing to one partner. Finally, feelings of social marginalization $(\mathrm{OR}=0.90, \mathrm{p}<.05)$ significantly lower the likelihood of being in the constant-one-partner trajectory.

\section{Summary and Discussion of Findings}

The findings of this study showed that part of the reason why being overweight delays the transition to first sexual intercourse is stigma-induced discriminatory treatment. weaker social relationships with peers. Overweight adolescents are less integrated into peer networks, more likely to feel excluded, less likely to have close friendship ties, and thus less likely to experience romantic relationships. These are key proximal factors contributing to their relatively late sexual debut. Although delayed first sex may be beneficial for overweight adolescents, it has different implications for youth when the association is understood in a broader social relationship context that reflects weight prejudice. That is, while being overweight is protective in slowing down the transition to early sexual intercourse, the process contributing to this outcome is negative for sound development. Overweight adolescents have later onset of first sex not because they learn to delay gratification, but because they are lacking the opportunities to interact closely with peers and thus develop intimate relationships from such context. Peer relationships in adolescence are building blocks for later development of interpersonal skills in adulthood. This lack of practice in cultivating relationship skills with same-sex as well as opposite-sex peers can have profound implications for later development. Adolescents who were rejected and ostracized by peers have elevated risk of adjustment problems in adulthood (Bagwell, Schmidt, Newcomb, and Bukowski 
2001). Problems in forming unions, such as cohabitation or marriage, can emerge because intimate relationship experiences in adolescence foster union formation in early adulthood (Raley, Crissey, and Muller 2007). Overweight adolescents may also experience more problems interacting with future fellow students in schools or coworkers in workplaces, both of which can hinder their socioeconomic attainment.

When developmental stages were taken into account, different processes emerged. Looking across the two sets of models for the younger and older ages in adolescence, the findings show that the relationships between weight status and social relationships vary by developmental stage. Most of these differences are likely a result of the different meanings of sexual behaviors for younger and older adolescents. By the time youth enter late adolescence and early adulthood, intimate relationship becomes more normative. Thus, sex is less likely to be associated with many factors that predict sexual acts in early and mid-adolescence, since everyone is engaging in a certain level of sexual behavior with their intimate partners.

There are two points to be noted. First, sociodemographic characteristics are better predictors of first sex in the younger ages than in the older ages. This is likely due to the fact that early risky sexual activity often correlates with a set of disadvantaged socioeconomic traits of an adolescent’s family of origin (Manlove, Ryan, and Franzetta 2007). In contrast, as noted in the emerging adulthood literature, identity exploration within intimate relationship is one of the major tasks during the period from ages 18 to 25 (Arnett 2000). As romantic relationships become more committed and serious than they were in adolescence, sexual relationships with an intimate partner also become more prevalent. It is thus reasonable that little variation by sociodemographic characteristics is observed. That is, adolescents of different races, maternal education, and family background are equally likely to explore emotional and physical intimacy 
with their partners.

Second, the negative relationship between overweight and timing of first sex is explained by the social relationship variables in the younger ages, not in the older ages. The peer context offers an important environment for adolescents to learn interpersonal relationship skills outside of their own family. They are learning to establish a sense of self and others through interactions with peers. Thus, younger adolescents are more influenced by the interactions they have with peers and the stigma attached to overweight. Research indicates that by late adolescence, there is a decline in the importance of belonging to a larger peer group, and an increase in the need to relate more intimately to selected significant others (Kroger 2006). This is probably why the negative association between overweight and sex debut is not attenuated by the social relationship variables as much as it is during younger teen ages. Another reason why the impact of social relationships is weaker than that of individual characteristics may be the normative nature of sexual activity in late adolescence and early adulthood.

The four intimate relationship trajectories depict different courses of development from adolescence to early adulthood. They highlight the importance of conceptualizing intimate relationship development as a process that plays out over time. While sex debut is a key life event for some teenagers, others proceed through adolescence without ever having such experience. There are still a few other adolescents who engage in early and multiple-partner sexual activities before they enter young adulthood. The characteristics of individuals in each trajectory (statistics not shown) indicate that the multiple-partner and the consistent-one-partner trajectories are relatively riskier paths than the progression-to-one-partner and the never-had-sex trajectories. Individuals in the former two trajectories are disadvantaged on several socioeconomic status indicators and have traits that lead to riskier sexual activities. One thing to 
be noted is that the constant-one-partner trajectory does not distinguish between having the same partner versus having different partners over time. It is very likely that within this trajectory, some youth are involved with a partner in a long-term relationship, whereas others are having serial relationships with different partners. The latter is more negative for an adolescent's development. It is very likely that the risky profile this trajectory shares with the high-risk trajectory is due to a considerable proportion of youth who are actually having serial sexual partners.

The analytical results of the multinomial logistic regression models again highlight the importance of teen social relationships in understanding sexual development among overweight adolescents. An important mechanism through which weight status affects the likelihood of being in any of the three sexual trajectories, relative to the never-had-sex trajectory, is the lower level of social integration among the overweight. Once the various social relationship variables were taken into account, overweight teens were not less likely to be on any of the three trajectories than normal-weight teens.

These results indicate that the friendship context in adolescence fosters the formation of intimate dyadic relationships and sets the stage for relationship development. Overweight adolescents, in particular, are vulnerable to being rejected or having less close relationships with peers. According to the literature on rejection sensitivity (Downey, Bonica, and Rincon 1999), the social exclusion and weight stigmatization experienced by overweight adolescents can sensitize them to future rejection. A defensive expectation of rejection or a readiness to perceive rejection can interfere with future opportunities to establish close friendships, because they prompt relationship avoidance and intensive/aggressive reactions toward potential rejection or ambiguous peer behavior. Overreacting rejection-sensitive teens can further establish a negative 
reputation among peers that reduces their chances for dating. All these processes show why overweight youth are particularly more likely to enter young adulthood without any sexual experience. In conclusion, the current study contributes to the existing literature by revealing the critical role of social relationships in the peer context as the incubator for the emergence of the first intimate sexual relationship and for subsequent intimate relationship development among overweight youth.

\section{NOTES}

${ }^{1}$ Among these adolescents, 2,637 had sex prior to Wave 1 and 1,286 became sexually active between Waves 1 and 2. Two sensitivity tests of the study sample were conducted (table available upon request). The first test regressed an indicator of first sex prior to Wave 1 on a set of time-invariant sociodemographic variables. Those who had sex prior to Wave 1 were significantly more likely to be older and Black, but less likely to be of 'other' race or to have a college-educated mother. They were also more likely to come from families with structures other than the twobiological-parent family. The second test was restricted to those who had never had sex at Wave 1 and regressed an indicator of first sex between Waves 1 and 2 on the same set of variables and weight status (measured by self-reports of BMI at Wave 1). Results were similar to those found in the previous test for the effects of sociodemographic characteristics. In addition, those who were excluded from the present analysis because they had become sexually active prior to Wave 2 were less likely to be underweight or overweight.

${ }^{2} \mathrm{BMI}$ is measured by converting height from inches to meters and weight from pounds to kilograms. BMI = [weight in kilograms (kg.) / height in meters squared $\left.\left(\mathrm{m}^{2}\right)\right]$. When "weight status" is mentioned hereafter, it refers to a composite measure that depicts both the height and weight of adolescents. Weight status will be used interchangeably with "body type" in this article.

${ }^{3}$ To ensure the findings are not significantly affected by the left censoring and the type of BMI used, comparisons were made between three models that utilize different types of BMI measures (and corresponding samples) from Wave 1 (self-reported BMI) and Wave 2 (self-reported and measured BMI). All the sociodemographic predictors in these models were measured at Wave 1 (table available upon request). The effects and significance level of all predictors are quite similar across the three models, regardless of the BMI measure used to construct the weight status categories. The only major difference between models is the stronger negative influence of underweight on timing of first sex when subjective BMI values are used to construct weight statuses. These results show that the decisions to start the study from Wave 2 and to use objective BMI to measure weight status do not influence the findings substantially.

${ }^{4}$ They reached the conclusion that these inconsistent reporting problems are largely random and have limited impact on the substantive conclusions about age at first sex, based on the seven strategies they employed to resolve the 
inconsistencies.

${ }^{5}$ The network file of Add Health only makes use of reports from respondents who attended schools that have response rates of 50 percent or higher (Moody 2005). Hence, depending on the variables in this file, the percentages of missing data range from one-fifth to about a quarter.

${ }^{6}$ The Bayesian Information Criterion (BIC) was used to decide the optimal number of groups (i.e., the model that has the lowest absolute value of BIC is the best). The comparison of BIC values indicated that the model with the best is a four-group specification. The model with four trajectories is used to extract sexual relationship trajectories from the data.

\section{REFERENCES}

Arnett, Jeffrey J. 2000. "Emerging Adulthood: A Theory of Development from the Late Teens through the Twenties." American Psychologist 55:469-480.

Bagwell, Catherine L., Michelle E. Schmidt, Andrew F. Newcomb, and William M. Bukowski. 2001. "Friendship and Peer Rejection as Predictors of Adult Adjustment." New Directions for Child and Adolescent Development 2001:25.

Bingham, C. Raymond and Lisa J. Crockett. 1996. "Longitudinal Adjustment Patterns of Boys and Girls Experiencing Early, Middle, and Late Sexual Intercourse." Developmental Psychology 32:647-58.

Brown, B. Bradford. 1999. "You're Going Out with Who?" Peer Group Influences on Adolescent Romantic Relationships." Pp. 291-329 in The Development of Romantic Relationships in Adolescence, edited by W. Furman, B. B. Brown, and C. Feiring. New York, NY: Cambridge University Press.

Buhi, Eric R. and Patricia Goodson. 2007. "Predictors of Adolescent Sexual Behavior and Intention: A Theory-Guided Systematic Review." Journal of Adolescent Health 40:4-21. Cavanagh, Shannon E. 2007. "The Social Construction of Romantic Relationships in Adolescence: Examining the Role of Peer Networks, Gender, and Race." Sociological Inquiry 77:572-600.

Cawley, John, Kara Joyner, and Jeffery Sobal. 2006. "Size Matters: The Influence of Adolescents' Weight and Height on Dating and Sex." Rationality and Society 18:67

Chen, Eunice Y. and Molly Brown. 2005. "Obesity Stigma in Sexual Relationships." Obesity Research 13:1393-1397.

Connolly, Jennifer A., Wendy Craig, Adele Goldberg, and Debra Pepler. 2004. "Mixed-Gender 
Groups, Dating, and Romantic Relationships in Early Adolescence." Journal of Research on Adolescence 14:185-207.

Connolly, Jennifer A., Wyndol Furman, and Roman Konarski. 2000. "The Role of Peers in the Emergence of Heterosexual Romantic Relationships in Adolescence." Child Development 71:1395-1408.

Costa, Frances M., Richard Jessor, John E. Donovan, and J. Dennis Fortenberry. 1995. "Early Initiation of Sexual Intercourse: The Influence of Psychosocial Unconventionality." Journal of Research on Adolescence 5:93-121.

Crockett, Lisa J., C. Raymond Bingham, Joanne S. Chopak, and Judith R. Vicary. 1996. "Timing of First Sexual Intercourse: The Role of Social Control, Social Learning, and Problem Behavior." Journal of Youth and Adolescence 25:89-111.

Dittus, Patricia J. and James Jaccard. 2000. "Adolescents' Perceptions of Maternal Disapproval of Sex: Relationship to Sexual Outcomes." Journal of Adolescent Health 26:268-278.

Downey, Geraldine, Cheryl Bonica, and Claudia Rincon. 1999. "Rejection Sensitivity and Adolescent Romantic Relationships." Pp. 148-174 in The development of romantic relationships in adolescence, edited by W. Furman, B. B. Brown, and C. Feiring. New York, NY: Cambridge University Press.

Feiring, Candice. 1999. "Other-Sex Friendship Networks and the Development of Romantic Relationships in Adolescence." Journal of Youth and Adolescence 28:495-512.

Goodman, Elizabeth, Beth R. Hinden, and Seema Khandelwal. 2000. "Accuracy of Teen and Parental Reports of Obesity and Body Mass Index." Pediatrics 106:52-58.

Gortmaker, Steven L., Aviva Must, James M. Perrin, Arthur M. Sobol, and William H. Dietz. 1993. "Social and Economic Consequences of Overweight in Adolescence and Young Adulthood." New England Journal of Medicine 329:1008-12.

Halpern, Carolyn Tucker, Kara Joyner, J. Richard Udry, and Chirayath Suchindran. 2000. "Smart Teens Don't Have Sex (or Kiss Much Either)." Journal of Adolescent Health 26:213-225. Halpern, Carolyn Tucker, Rosalind Berkowitz King, Selene G Oslak, and J. Richard Udry. 2005. "Body Mass Index, Dieting, Romance, and Sexual Activity in Adolescent Girls: Relationships Over Time." Journal of Research on Adolescence 15:535-559.

Halpern, Carolyn Tucker, J. Richard Udry, Benjamin C. Campbell, and and Chirayath M. 
Suchindran. 1999. "Effects of Body Fat on Weight Concerns, Dating and Sexual Activity: A Longitudinal Analysis of Black and White Adolescent Girls." Developmental Psychology 35:721-736.

Harris, Kathleen Mullan, Francesca Florey, Joyce Tabor, Peter S. Bearman, Jo Jones, and J. Richard Udry. 2003. "The National Longitudinal Study of Adolescent Health: Research Design." [WWW document]. URL: http://www.cpc.unc.edu/projects/addhealth/design. Hofferth, Sandra L. 1987. Risking the Future: Initiation of Sexual Intercourse. Washington, DC: National Academy Press.

Jemmott, Loretta Sweet and John B. Jemmott. 1992. "Family Structure, Parental Strictness, and Sexual Behavior among Inner-City Black Male Adolescents." Journal of Adolescent Research 7:192-207.

Kiess, Wieland and Antje Boettner. 2002. "Obesity in the Adolescent." Adolescent Medicine 13:181-190.

Kroger, Jane. 2006. "Identity in Late Adolescence." Pp. 87-114 in Identity Development: Adolescence Through Adulthood. Thousand Oaks, California: Sage.

Latner, J. D. and A. J. Stunkard. 2003. "Getting Worse: The stigmatization of obese children." Obesity Research 11:452-456.

Luster, Tom and Stephen A. Small. 1994. "Factors Associated with Sexual Risk-Taking Behaviors among Adolescents." Journal of Marriage and Family 56:622-632.

Manlove, Jennifer S., Suzanne Ryan, and Kerry Franzetta. 2007. "Risk and Protective Factors Associated with the Transition to a First Sexual Relationship with an Older Partner." Journal of Adolescent Health 40:135-143.

McDanal Jr, Clarence E. 1993. "Obesity, Multiple Personality Disorder, and Hypnosis." American Journal of Psychiatry 150:1274.

Miller, Brent C., Roger B. Christensen, and Terrance D. Olson. 1987. "Adolescent Self-Esteem in Relation to Sexual Attitudes and Behavior." Youth \& Society 19:93-111.

Moody, James. 2005. "Add Health Network Structure Files." Carolina Population Center, University of North Carolina at Chapel Hill.

Nagin, Daniel 2005. Group-Based Modeling of Development: Harvard University Press.

NCHS. 2005. "Prevalence of Overweight Among Children and Adolescents: United States, 1999- 
2002." Available online at:

http://www.cdc.gov/nchs/products/pubs/pubd/hestats/overwght99.htm.

Ogden, Cynthia L., Robert J. Kuczmarski, Katherine M. Flegal, Zuguo Mei, Shumei Guo, Rong

Wei, Laurence M. Grummer-Strawn, Lester R. Curtin, Alex F. Roche, and Clifford L. Johnson. 2002. "Centers for Disease Control and Prevention 2000 Growth Charts for the United States: Improvements to the 1977 National Center for Health Statistics Version." Pediatrics 109:45-60.

Pearce, Michelle J., Julie Boergers, and Mitchell J. Prinstein. 2002. "Adolescent Obesity, Overt and Relational Peer Victimization, and Romantic Relationships." Obesity Research 10:386393.

Puhl, R. M. and J. D. Latner. 2007. "Stigma, Obesity, and the Health of the Nation's Children." Psychological Bulletin 133:557-580.

Raley, R. Kelly, Sarah Crissey, and Chandra Muller. 2007. "Of Sex and Romance: Late Adolescent Relationships and Young Adult Union Formation." Journal of Marriage and Family 69:1210-1226.

Rubin, Donald B. 2004. Multiple Imputation for Nonresponse in Surveys. New York: J. Wiley \& Sons.

Ryan, Suzanne, Jennifer Manlove, and and Kerry Franzetta. 2003. "The First Time:

Characteristics of Teens' First Sexual Relationships. Child Trends Research Brief. Publication\# 2003-16." Child Trends, Washington, DC.

Santelli, John S., Nancy D. Brener, Richard Lowry, Amita Bhatt, and Laurie S. Zabin. 1998.

"Multiple Sexual Partners Among US Adolescents and Young Adults." Family Planning Perspectives 30:271-275.

Sieving, Renee E., Marla E. Eisenberg, Sandra Pettingell, and Carol Skay. 2006. "Friends' Influence on Adolescents' First Sexual Intercourse." Perspectives on Sexual and Reproductive Health 38:13-19.

Sieving, Renee E., Clea S. McNeely, and Robert W. Blum. 2000. "Maternal Expectations, Mother-Child Connectedness, and Adolescent Sexual Debut." Archives of Pediatrics and Adolescent Medicine 154:809-816.

Strauss, Richard S. and Harold A. Pollack. 2003. "Social Marginalization of Overweight Children." Archives of Pediatrics and Adolescent Medicine 157:746-752. 
Thornton, Arland. 1990. "The Courtship Process and Adolescent Sexuality." Journal of Family Issues 11:239-273.

Upchurch, Dawn M., Lee A. Lillard, Carol S. Aneshensel, and Nicole Fang Li. 2002. "Inconsistencies in Reporting the Occurence and Timing of First Intercourse among Adolescents." The Journal of Sex Research 39:197-206.

Whitbeck, Les B., Kevin A. Yoder, Dan R. Hoyt, and Rand D. Conger. 1999. "Early Adolescent Sexual Activity: A Developmental Study." Journal of Marriage and Family 61:934-946.

Wiederman, Michael W. and Shannon R. Hurst. 1998. "Body Size, Physical Attractiveness, and Body Image among Young Adult Women: Relationships to Sexual Experience and Sexual Esteem." The Journal of Sex Research 35:272-281. 
Table 1: Summary statistics of adolescent characteristics by weight status, Add Health, N=6905

\begin{tabular}{|c|c|c|c|c|c|c|c|c|}
\hline \multirow{2}{*}{$\begin{array}{l}\text { Unweighted N } \\
\text { Measured BMI (w2) }\end{array}$} & \multirow{2}{*}{$\begin{array}{c}\begin{array}{c}\text { All Respondents } \\
(\mathrm{N}=6905)\end{array} \\
22.66\end{array}$} & \multicolumn{2}{|c|}{$\begin{array}{l}\text { Underweight } \\
(\mathrm{N}=230)\end{array}$} & \multirow{2}{*}{$\begin{array}{l}\begin{array}{l}\text { Normal weight } \\
(\mathrm{N}=4668)\end{array} \\
20.51\end{array}$} & \multicolumn{2}{|c|}{$\begin{array}{l}\text { At risk of overweight } \\
(\mathrm{N}=1013)\end{array}$} & \multicolumn{2}{|c|}{$\begin{array}{c}\text { Overweigh } \\
(\mathrm{N}=994)\end{array}$} \\
\hline & & 17.46 & & & 24.95 & & 31.23 & \\
\hline \% had first sex between W2 \& W3 & 83.67 & 78.66 & $*$ & 84.88 & 83.67 & & 79.30 & $* *$ \\
\hline Age at first sexual intercourse & 17.36 & 18.15 & $* * *$ & 17.37 & 17.04 & $* *$ & 17.48 & \\
\hline \multicolumn{9}{|l|}{ Basic socio-demographics } \\
\hline Age at Wave 2 & 15.46 & 15.98 & & 15.49 & 15.18 & & 15.47 & \\
\hline \multicolumn{9}{|l|}{ Gender (\%) } \\
\hline males & 49.43 & 60.09 & $*$ & 47.93 & 48.74 & & 54.57 & $* *$ \\
\hline females & 50.57 & 39.91 & $*$ & 52.07 & 51.26 & & 45.43 & $* *$ \\
\hline \multicolumn{9}{|l|}{ Race (\%) } \\
\hline White & 69.96 & 71.85 & & 71.37 & 65.82 & $*$ & 67.65 & $\dagger$ \\
\hline Black & 12.42 & 5.66 & $*$ & 11.20 & 15.99 & $* * *$ & 15.74 & $* * *$ \\
\hline Hispanic & 11.90 & 10.19 & & 11.38 & 13.46 & & 12.99 & \\
\hline Other & 5.72 & 12.30 & $* *$ & 6.05 & 4.73 & & 3.62 & $\dagger$ \\
\hline \multicolumn{9}{|l|}{ Family structure (\%) } \\
\hline 2-bio-parents family & 63.41 & 52.51 & $\dagger$ & 70.41 & 57.22 & & 63.82 & $\dagger$ \\
\hline step family & 14.15 & 22.51 & & 10.11 & 17.65 & & 13.86 & $\dagger$ \\
\hline single family & 19.77 & 21.87 & & 17.19 & 21.61 & & 20.04 & $* *$ \\
\hline other family & 2.67 & 3.11 & & 2.29 & 3.52 & $*$ & 2.28 & \\
\hline \multicolumn{9}{|l|}{ Maternal education (\%) } \\
\hline less than HS & 15.18 & 12.74 & & 15.50 & 15.33 & $\dagger$ & 14.98 & $* * *$ \\
\hline High school & 41.35 & 45.23 & & 38.73 & 43.22 & $*$ & 41.55 & $* * *$ \\
\hline Some college & 17.81 & 13.67 & * & 16.79 & 18.63 & & 18.11 & $*$ \\
\hline College and beyond & 25.66 & 28.36 & & 28.98 & 22.83 & $* * *$ & 25.36 & $* * *$ \\
\hline Family Income (in thousands) & 50.46 & 51.57 & & 53.02 & 45.66 & $* *$ & 43.66 & $* * *$ \\
\hline \multicolumn{9}{|l|}{ Factors related to first sex } \\
\hline Mother-child closeness & 17.22 & 17.00 & & 17.21 & 17.29 & & 17.28 & \\
\hline Protective factors & 11.64 & 11.48 & & 11.66 & 11.60 & & 11.63 & \\
\hline Self-reported grades & 2.94 & 2.89 & $\dagger$ & 3.00 & 2.87 & $* * *$ & 2.73 & $* * *$ \\
\hline School adjustment & 22.02 & 21.02 & $* *$ & 22.15 & 21.96 & & 21.70 & $*$ \\
\hline Self esteem & 33.07 & 32.55 & $*$ & 33.45 & 32.74 & $* * *$ & 31.76 & $* * *$ \\
\hline Religiosity & 8.80 & 8.37 & $*$ & 8.85 & 8.72 & & 8.79 & \\
\hline R's attractiveness & 3.55 & 3.35 & $* * *$ & 3.67 & 3.46 & $* * *$ & 3.18 & $* * *$ \\
\hline Motivation to have sex & 13.10 & 13.31 & & 13.02 & 13.13 & & 13.37 & $\dagger$ \\
\hline Perceived social consequences of sex & 8.74 & 8.74 & & 8.81 & 8.62 & & 8.58 & \\
\hline \multicolumn{9}{|l|}{ Social Relationship Characteristics } \\
\hline Feeling of socially marginalized & 2.17 & 2.44 & $*$ & 2.10 & 2.16 & & 2.41 & $* * *$ \\
\hline Number of received friendship nominations & 4.86 & 5.11 & & 5.23 & 4.51 & & 3.52 & $* * *$ \\
\hline Closeness with same-sex friends & 7.94 & 7.57 & & 8.15 & 7.80 & & 7.24 & $* *$ \\
\hline Closeness with opposite-sex friends & 4.52 & 4.11 & & 4.66 & 4.34 & & 4.14 & $*$ \\
\hline Played team sport in the past week & 1.53 & 1.19 & $* * *$ & 1.57 & 1.53 & & 1.46 & $*$ \\
\hline Had romantic relationship by w2 (\%) & 45.54 & 38.21 & $* *$ & 49.61 & 39.68 & $* * *$ & 34.94 & $* * *$ \\
\hline \multicolumn{9}{|l|}{ Sexual Relationship Trajectory (\%) } \\
\hline High-risk multiple partner trajectory & 2.34 & 0.93 & & 2.51 & 2.55 & & 1.70 & \\
\hline Constant-one-partner trajectory & 40.03 & 36.09 & & 41.35 & 39.91 & & 35.02 & $*$ \\
\hline Progression-to-one-partner trajectory & 41.29 & 41.64 & & 41.04 & 41.22 & & 42.41 & \\
\hline Never-had-sex trajectory & 16.34 & 21.34 & $\dagger$ & 15.10 & 16.32 & & 20.88 & $* *$ \\
\hline
\end{tabular}

T-test against normal weight adolescents: $\dagger \mathrm{p}<.10$; ${ }^{*} \mathrm{p}<.05 ;{ }^{* *} \mathrm{p}<.01 ; * * * \mathrm{p}<.001$ 
Table 2: Odds ratios of discrete-time event history models predicting transition to first sexual intercourse, Add Health data (weighted \& multiply imputed data), N=6,905

\begin{tabular}{|c|c|c|c|c|}
\hline & Model 1 & Model 2 & Model 3 & Model 4 \\
\hline \multicolumn{5}{|l|}{ Weight Statuses } \\
\hline Underweight & $0.75 *$ & $0.77 *$ & $0.77 *$ & 0.81 \\
\hline Normal Weight (ref.) & --- & --- & --- & --- \\
\hline At risk of overweight & 0.98 & 0.94 & 0.96 & 1.01 \\
\hline Overweight & $0.82 * *$ & $0.78 * * *$ & $0.81 * *$ & $0.89 \dagger$ \\
\hline Age (time-varying) & $1.10 * * *$ & $1.11 * * *$ & $1.13^{* * *}$ & $1.15^{* * *}$ \\
\hline Male & 0.98 & 0.98 & $0.76^{* * *}$ & $0.80 * * *$ \\
\hline \multicolumn{5}{|l|}{ Race } \\
\hline White (ref.) & & --- & --- & --- \\
\hline Black & & 1.16 & 1.09 & $1.28 * *$ \\
\hline Hispanics & & 0.89 & $0.82 *$ & $0.85^{*}$ \\
\hline Other & & $0.69 * * *$ & $0.70 * * *$ & $0.78^{*}$ \\
\hline \multicolumn{5}{|l|}{ Maternal Education } \\
\hline Less than High School (ref.) & & --- & --- & --- \\
\hline High School & & 1.03 & 1.04 & 0.99 \\
\hline Some College & & 0.96 & 0.99 & 0.90 \\
\hline College and beyond & & $0.79 * *$ & $0.86 \dagger$ & $0.77 * *$ \\
\hline \multicolumn{5}{|l|}{ Family Structure } \\
\hline Two-biological-parent families (ref.) & & --- & --- & --- \\
\hline Stepfamilies & & $1.46 * * *$ & $1.27 * * *$ & $1.25^{* * *}$ \\
\hline Single-parent families & & $1.32 * * *$ & 1.11 & 1.11 \\
\hline Other families & & 1.10 & 0.96 & 0.93 \\
\hline Family income & & 1.00 & 1.00 & 1.00 \\
\hline Mother-child closeness & & & 1.02 & 1.02 \\
\hline Positive family climate & & & $0.93^{* * *}$ & $0.94^{* * *}$ \\
\hline Self-reported grades & & & $0.82 * * *$ & $0.81 * * *$ \\
\hline School adjustment & & & 0.99 & $0.99 *$ \\
\hline Self esteem & & & $1.02 *$ & 1.01 \\
\hline Religiosity & & & 0.99 & $0.98 \dagger$ \\
\hline R's attractiveness & & & $1.17^{* * *}$ & $1.11^{* * *}$ \\
\hline Motivation to have sex & & & $1.04 * * *$ & $1.04 * * *$ \\
\hline Perceived social consequences of sex & & & $0.91 * * *$ & $0.92 * * *$ \\
\hline Feelings of social marginalization & & & & $0.95 * *$ \\
\hline Number of received friendship nominat & & & & $1.03 * * *$ \\
\hline Closeeness with same-sex friends & & & & $1.02 * *$ \\
\hline Closeeness with opposite-sex friends & & & & 1.01 \\
\hline Participate in a team sport in past week & & & & $1.07 * *$ \\
\hline Ever had a romantic relationship & & & & $1.72 * * *$ \\
\hline Total person years & 23221 & 23221 & 23221 & 23221 \\
\hline
\end{tabular}


Table 3: Odds ratios of discrete time event history analyses predicting transition to first sexual intercourse by exposure age, Add Health data (weighted \& multiply imputed data)

\begin{tabular}{|c|c|c|c|c|c|c|c|c|}
\hline & \multicolumn{4}{|c|}{ Exposure age $<=17$} & \multicolumn{4}{|c|}{ Exposure age $>=18$} \\
\hline & Model 1 & Model 2 & Model 3 & Model 4 & Model 1 & Model 2 & Model 3 & Model 4 \\
\hline \multicolumn{9}{|l|}{ Weight Statuses } \\
\hline Underweight & $0.56 * *$ & $0.59 * *$ & $0.57 * *$ & $0.58 *$ & 0.96 & 0.98 & 1.00 & 1.08 \\
\hline Normal Weight (ref.) & --- & --- & --- & --- & --- & --- & --- & --- \\
\hline At risk of overweight & 1.07 & 1.03 & 1.05 & 1.11 & 0.94 & 0.92 & 0.94 & 0.98 \\
\hline Overweight & $0.84 *$ & $0.77 * *$ & $0.79 *$ & 0.90 & $0.79 * *$ & $0.76^{* * *}$ & $0.81^{* *}$ & $0.85 *$ \\
\hline Age (time-varying) & $1.55^{* * *}$ & $1.58 * * *$ & $1.60 * * *$ & $1.62 * * *$ & $0.78 * * *$ & $0.79 * * *$ & $0.80 * * *$ & $0.81 * * *$ \\
\hline Male & 0.97 & 0.99 & $0.74 * * *$ & $0.79 * *$ & 0.96 & 0.95 & $0.75^{* * *}$ & $0.76^{* *}$ \\
\hline \multicolumn{9}{|l|}{ Race } \\
\hline White (ref.) & & --- & --- & --- & & --- & --- & --- \\
\hline Black & & $1.30 * *$ & $1.20 \dagger$ & $1.41 * * *$ & & 1.04 & 0.99 & 1.16 \\
\hline Hispanics & & 0.87 & $0.81^{*}$ & 0.85 & & 0.93 & 0.85 & 0.87 \\
\hline Other & & $0.57 * * *$ & $0.58 * * *$ & $0.67 *$ & & $0.81 *$ & $0.82 *$ & 0.88 \\
\hline \multicolumn{9}{|l|}{ Maternal Education } \\
\hline Less than High School (ref.) & & --- & --- & --- & & --- & --- & --- \\
\hline High School & & 0.92 & 0.95 & 0.90 & & 1.14 & 1.12 & 1.08 \\
\hline Some College & & 0.83 & 0.87 & $0.78^{*}$ & & 1.13 & 1.12 & 1.03 \\
\hline College and beyond & & $0.69 * * *$ & $0.79 *$ & $0.70 * *$ & & 0.89 & 0.91 & $0.82 \dagger$ \\
\hline \multicolumn{9}{|l|}{ Family Structure } \\
\hline Two-biological-parent families (ref.) & & --- & --- & --- & & --- & --- & --- \\
\hline Stepfamilies & & $1.57 * * *$ & $1.33^{* * *}$ & $1.31 * *$ & & $1.29 *$ & 1.18 & 1.17 \\
\hline Single-parent families & & $1.44 * * *$ & $1.21 *$ & $1.20^{*}$ & & $1.20 \dagger$ & 1.03 & 1.03 \\
\hline Other families & & 1.34 & 1.13 & 1.10 & & 0.96 & 0.88 & 0.86 \\
\hline Family income & & 1.00 & 1.00 & 1.00 & & 1.00 & 1.00 & 1.00 \\
\hline Mother-child closeness & & & 1.00 & 1.01 & & & $1.03 \dagger$ & $1.04 \dagger$ \\
\hline Positive family climate & & & $0.94^{* *}$ & $0.95^{* *}$ & & & $0.94 * *$ & $0.94 * *$ \\
\hline Self-reported grades & & & $0.77 * * *$ & $0.76 * * *$ & & & $0.87 * *$ & $0.86^{* *}$ \\
\hline School adjustment & & & $0.98 *$ & $0.97 * *$ & & & 1.01 & 1.01 \\
\hline Self esteem & & & $1.02 *$ & 1.02 & & & $1.02 \dagger$ & 1.01 \\
\hline Religiosity & & & $0.98 \dagger$ & $0.97 *$ & & & 0.99 & 0.98 \\
\hline R's attractiveness & & & $1.15^{* * *}$ & $1.09 *$ & & & $1.19 * * *$ & $1.13^{*}$ \\
\hline Motivation to have sex & & & $1.04 * * *$ & $1.04 * * *$ & & & $1.04 * *$ & $1.04^{* *}$ \\
\hline Perceived social consequences of sex & & & $0.90^{* * *}$ & $0.91^{* * *}$ & & & $0.93 * *$ & $0.94 * *$ \\
\hline Feelings of social marginalization & & & & $0.93 * *$ & & & & 0.97 \\
\hline Number of received friendship nomination & & & & $1.04 * *$ & & & & $1.03 * *$ \\
\hline Closeeness with same-sex friends & & & & $1.01 \dagger$ & & & & $1.02 *$ \\
\hline Closeeness with opposite-sex friends & & & & $1.02 *$ & & & & 1.00 \\
\hline Participate in a team sport in past week & & & & 1.03 & & & & $1.12 * * *$ \\
\hline Ever had a romantic relationship & & & & $1.90^{* * *}$ & & & & $1.47 * * *$ \\
\hline Total N & 5969 & 5969 & 5969 & 5969 & 3974 & 3974 & 3974 & 3974 \\
\hline Total person years & 13454 & 13454 & 13454 & 13454 & 9767 & 9767 & 9767 & 9767 \\
\hline
\end{tabular}


Table 4: Multinomial logistic regression models predicting sexual relationship trajectories, Add Health data (multiply and imputed data) $\mathrm{N}=6,905$

\begin{tabular}{|c|c|c|c|c|c|c|c|c|c|c|c|c|}
\hline \multirow{2}{*}{ (Reference: Never-had-sex trajectory) } & \multicolumn{3}{|c|}{ Model 1} & \multicolumn{3}{|c|}{ Model 2} & \multicolumn{3}{|c|}{ Model 3} & \multicolumn{3}{|c|}{ Model 4} \\
\hline & High risk & Always1 & $0->1$ & High risk & Always1 & $0->1$ & High risk & Always1 & $0->1$ & High risk & Always1 & $0->1$ \\
\hline \multicolumn{13}{|c|}{ Weight Statuses } \\
\hline Underweight & 0.25 & $0.58 *$ & 0.78 & 0.27 & $0.63 \dagger$ & 0.82 & 0.25 & 0.65 & 0.87 & 0.30 & 0.76 & 0.96 \\
\hline Normal Weight (ref.) & -- & -- & -- & -- & -- & -- & -- & -- & -- & -- & -- & -- \\
\hline At risk of overweight & 0.99 & 0.92 & 0.88 & 0.98 & 0.87 & 0.86 & 0.96 & 0.86 & 0.87 & 1.19 & 1.01 & 0.95 \\
\hline Overweight & $0.50 *$ & $0.61 * * *$ & $0.75^{*}$ & $0.48^{*}$ & $0.56^{* * *}$ & $0.73^{*}$ & $0.50 \dagger$ & $0.60 * *$ & $0.77 \dagger$ & 0.68 & $0.75 \dagger$ & 0.87 \\
\hline Age at w2 & $1.19 *$ & $1.11^{*}$ & $0.84^{* * *}$ & $1.22 *$ & $1.13^{*}$ & $0.84^{* * *}$ & $1.17 \dagger$ & $1.10 \dagger$ & $0.85^{* * *}$ & $1.14^{* * *}$ & 1.09 & $0.85^{* * *}$ \\
\hline Male & 0.68 & 0.98 & 0.99 & 0.68 & 1.00 & 0.99 & $0.28 * * *$ & $0.59 * * *$ & $0.74 * *$ & 0.34 & $0.68 *$ & $0.75^{*}$ \\
\hline \multicolumn{13}{|l|}{ Race } \\
\hline White (ref.) & & & & -- & -- & -- & -- & -- & -- & -- & -- & -- \\
\hline Black & & & & 1.00 & 1.29 & 1.03 & $0 . .85$ & 1.10 & 0.92 & 1.39 & $1.58^{*}$ & 1.09 \\
\hline Hispanics & & & & 0.51 & 0.80 & 1.00 & $0.43 \dagger$ & $0.69 *$ & 0.92 & 0.48 & 0.75 & 0.94 \\
\hline Other & & & & 0.62 & $0.43^{* * *}$ & $0.67 *$ & 0.57 & $0.42 * * *$ & $0.65 *$ & 0.83 & $0.56 * *$ & 0.76 \\
\hline \multicolumn{13}{|l|}{ Matemal Education } \\
\hline Less than High School (ref.) & & & & -- & -- & -- & -- & -- & -- & -- & -- & -- \\
\hline High School & & & & 1.41 & 0.98 & 1.02 & 1.37 & 0.95 & 0.97 & 1.18 & 0.82 & 0.89 \\
\hline Some College & & & & 0.96 & 0.93 & 1.08 & 0.92 & 0.93 & 1.04 & 0.71 & 0.73 & 0.91 \\
\hline College and beyond & & & & 1.03 & $0.66^{*}$ & 0.85 & 1.21 & $0.74 \dagger$ & 0.86 & 0.88 & $0.55^{* *}$ & 0.73 \\
\hline \multicolumn{13}{|l|}{ Family Structure } \\
\hline 2-bio-parent families (ref.) & & & & -- & -- & -- & -- & -- & -- & -- & -- & -- \\
\hline Step families & & & & $2.98 * *$ & $2.29 * * *$ & $1.62^{* *}$ & $1.95 \dagger$ & $1.72^{* *}$ & $1.42 *$ & $1.92 \dagger$ & $1.75^{* *}$ & $1.44^{*}$ \\
\hline Single families & & & & $1.89 *$ & $1.57^{* *}$ & 1.24 & 1.17 & 1.13 & 1.06 & 1.11 & 1.11 & 1.05 \\
\hline Other families & & & & 1.48 & 1.25 & 0.84 & 1.01 & 0.98 & 0.77 & 0.76 & 0.88 & 0.72 \\
\hline Family income & & & & 1.00 & 1.00 & 1.00 & 1.00 & 1.00 & 1.00 & 1.00 & 1.00 & 1.00 \\
\hline Mother-child closeness & & & & & & & 1.08 & 1.04 & $1.07 *$ & 1.09 & 1.04 & $1.07 \dagger$ \\
\hline Positive family climate & & & & & & & $0.74 * * *$ & $0.84^{* * *}$ & $0.90 *$ & $0.76^{* * *}$ & $0.86 * *$ & $0.91^{*}$ \\
\hline Self-reported grades & & & & & & & $0.62 * *$ & $0.63^{* * *}$ & $0.80^{* *}$ & $0.59^{* *}$ & $0.59 * * *$ & $0.76^{* *}$ \\
\hline School adjustment & & & & & & & 0.98 & 1.00 & 1.01 & 0.96 & 0.99 & 1.00 \\
\hline Self esteem & & & & & & & $1.06^{*}$ & $1.05^{* *}$ & 1.02 & 1.03 & 1.03 & 1.01 \\
\hline Religiosity & & & & & & & 0.93 & 0.98 & 1.00 & 0.91 & 0.96 & 0.98 \\
\hline R's attractiveness & & & & & & & $1.45^{* *}$ & $1.40 * * *$ & $1.28 * * *$ & 1.25 & $1.25 * *$ & $1.20 *$ \\
\hline Motivation to have sex & & & & & & & $1.17^{* * *}$ & $1.08^{* * *}$ & $1.05 \dagger$ & $1.17^{* *}$ & $1.08^{* *}$ & 1.04 \\
\hline Perceived social consequences of sex & & & & & & & $0.77 * * *$ & $0.82^{* * *}$ & $0.89^{* *}$ & $0.80^{* *}$ & $0.84 * * *$ & $0.90^{* *}$ \\
\hline Feelings of social marginalization & & & & & & & & & & 0.87 & $0.90^{*}$ & 1.00 \\
\hline Number of received friendship nomin & nations & & & & & & & & & $1.08^{*}$ & $1.08^{* * *}$ & $1.05^{* *}$ \\
\hline Closeeness with same-sex friends & & & & & & & & & & 1.03 & $1.05^{* *}$ & $1.03 \dagger$ \\
\hline Closeeness with opposite-sex friends & & & & & & & & & & $1.05 \dagger$ & 1.03 & 1.00 \\
\hline Participate in a team sport in past wee & & & & & & & & & & 1.12 & $1.15^{* *}$ & $1.19 * * *$ \\
\hline Ever had a romantic relationship & & & & & & & & & & $8.91^{* * *}$ & $3.84 * * *$ & $1.98 * * *$ \\
\hline
\end{tabular}


Figure 1: Trajectories of sexual relationship from adolescence to young adulthood

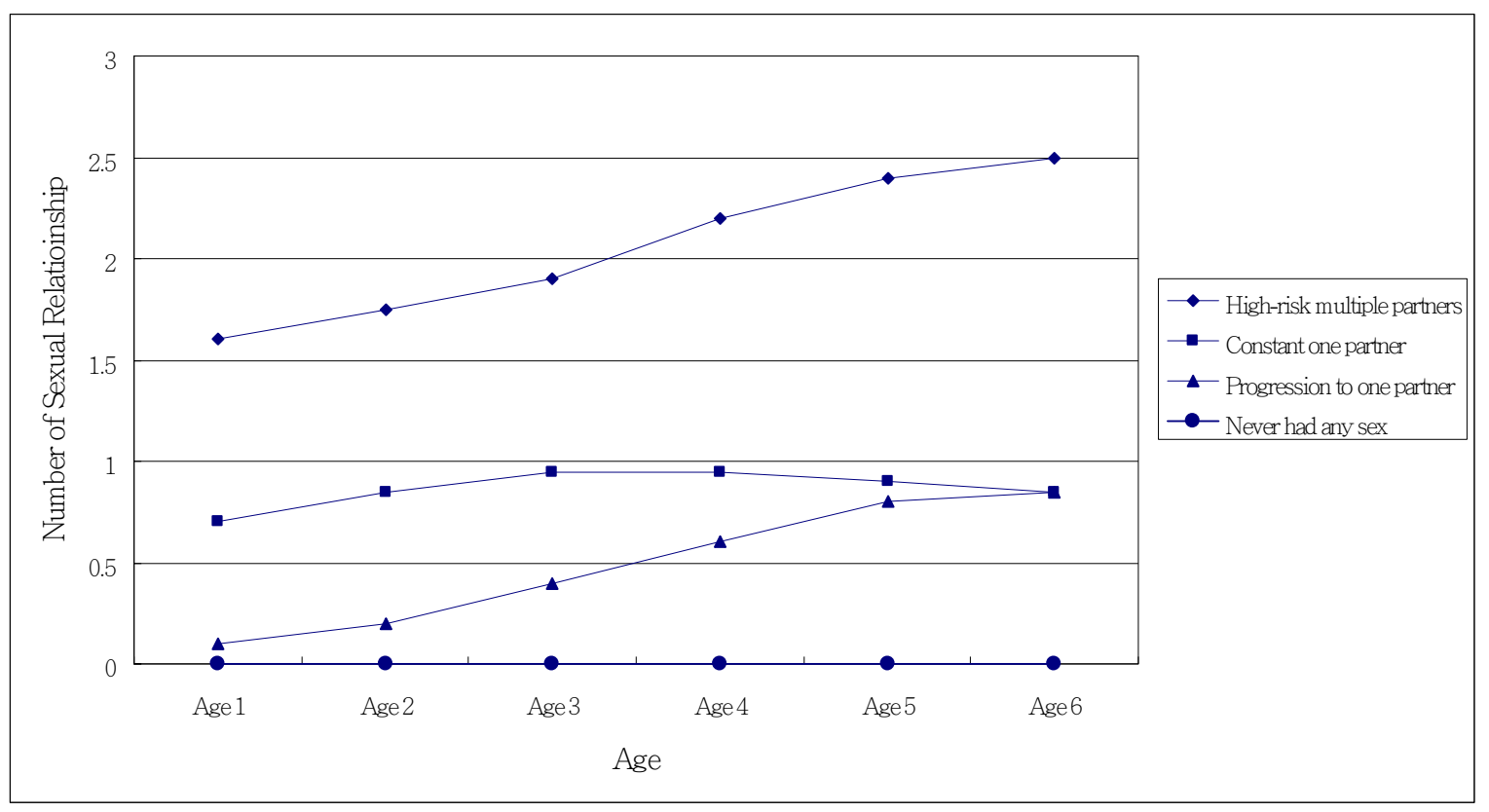

